\title{
Numerical study of heat transfer and solute distribution in hybrid laser-MIG welding
}

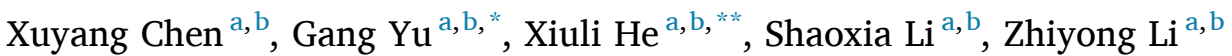 \\ ${ }^{a}$ Key Laboratory of Mechanics in Advanced Manufacturing, Institute of Mechanics, Chinese Academy of Sciences, Beijing, 100190, China \\ ${ }^{\mathrm{b}}$ School of Engineering Science, University of Chinese Academy of Sciences, Beijing, 100049, China
}

\section{A R T I C L E I N F O}

\section{Keywords:}

Hybrid laser-MIG welding

Aluminum alloy

Heat transfer

Solute distribution

\begin{abstract}
A B S T R A C T
In the quest for the transport mechanism in the molten pool during hybrid laser-MIG welding of aluminum alloy, an improved three-dimensional numerical model is developed. A modified model for laser heat source is utilized to investigate the energy absorption mechanism in keyhole. Some driving forces are considered to simulate the fluid flow, such as electromagnetic force, surface tension and buoyancy. The effects of arc pressure and droplet impact are taken into account to track the free surface. Several dimensionless numbers are utilized to analyze the relative importance of driving forces. The temperature field, liquid velocity field and magnesium and zinc distribution are numerically and experimentally studied. Results shows that the laser beam create a great impression on the heat transfer, fluid flow, solute distribution and weld bead geometry. In MIG welding, there is an insufficient mixing zone at the front of the pool, while the solute distribution in hybrid laser-MIG welding is observed more uniform. Magnesium and zinc are found concentrated in lower and upper part of the molten pool, respectively. The mathematical model is well validated by the experimental observations, and the calculated element distribution agrees well with the experimental measurements. Furthermore, the improved model provides an effective method for parametric optimization to improve the properties of hybrid laser-MIG welding joints.
\end{abstract}

\section{Introduction}

The hybrid laser-MIG (metal inert gas) welding, which combined the laser beam welding and gas metal arc welding, was widely used in manufacturing industry [1,2]. The hybrid welding enhanced the advantages of individual process, and resulted in stronger robustness for industrial application with characteristics of high speed, deep penetration, less deformation and ability to bridge larger gap [3]. The hybrid laser-MIG welding is a complex physical process, including keyhole, additional metal, thermal behavior, fluid flow, mass transfer, solute redistribution, vapor and spatter etc [4-6]. To understand underlying mechanism and obtain expected mechanical properties, the choice of appropriate welding parameters were essential [7]. It was well known that temperature and composition had determining effect on final microstructure and weldment performance [8-10]. Therefore, investigation of heat and mass transfer mechanism was very helpful to optimize processing parameters and achieve desired weld seam quality.

In recent years, several numerical simulations for laser-arc welding were developed. Zhou et al. [11] studied the transport phenomena for hybrid laser-MIG keyhole welding through a developed two-dimensional computation model. In the model, to handle solid phase, liquid phase and mushy zone, the continuum formulation was used during the processes of melting and solidification. They considered the influence of energy transportation, fluid flow, and interaction between weld pool and droplets in their calculation. A computational model to investigate the dynamic development process of the weld pool for stationary hybrid laser-MIG welding was established by Gao et al. [12]. They calculated the shape of weld pool and transient velocity distribution of liquid metal, and the calculated weld bead geometry agreed well with experimental measured geometry. Piekarska et al. [6] developed a model to calculate the temperature and liquid velocity field of the melt pool. In their model, different heat source modules for laser and arc, buoyancy and liquid flow were considered, and the results were verified by experiments. Bendaoud et al. [13] simulated UR2507Cu duplex steel with high thickness and Y-shaped chamfer geometry. In their model, a numerical exploratory method was used to determine the parameters for heat source in order to minimize the difference between

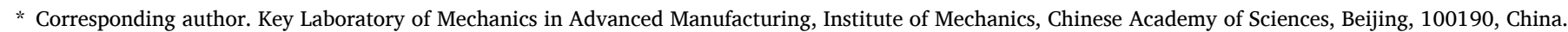

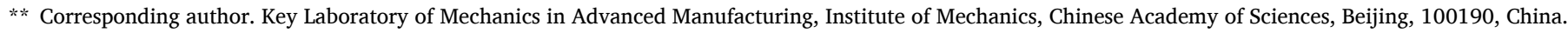

E-mail addresses: gyu@imech.ac.cn (G. Yu), xlhe@imech.ac.cn (X. He).
} 


\begin{tabular}{|c|c|c|c|}
\hline \multicolumn{2}{|c|}{ Nomenclature } & $g$ & Acceleration due to gravity \\
\hline$t$ & Time & $h_{c}$ & Heat transfer coefficient \\
\hline$x_{i}$ & Distance along $i$ directions & $t_{b x}$ & Tangential unit vector parallel to the $\mathrm{x}-\mathrm{z}$ plane \\
\hline$u_{j}$ & Liquid velocity along $j$ direction & $t_{b y}$ & Tangential unit vector parallel to the $y-z$ plane \\
\hline$P$ & Pressure & $n_{b}$ & Outward normal vector \\
\hline$V$ & Scanning speed & $f$ & Frequency of droplet transfer \\
\hline$f_{l}$ & Liquid fraction & $\rho_{w}$ & Density of welding wire \\
\hline$C_{p}$ & Specific heat & $C_{w}$ & Specific heat capacity of welding wire \\
\hline$\Delta H$ & Latent heat content & $d_{w}$ & Wire diameter \\
\hline$F$ & Volume force & $U_{w}$ & Wire feed speed \\
\hline$F_{L x}$ & Electromagnetic force along $\mathrm{x}$ direction & $T$ & Temperature \\
\hline$F_{L y}$ & Electromagnetic force along y direction & $T_{w}$ & Droplet temperature \\
\hline$F_{L z}$ & Electromagnetic force along $\mathrm{z}$ direction & $T_{l}$ & Liquidus temperature \\
\hline$h$ & Sensible heat enthalpy & $T_{r e f}$ & Reference temperature \\
\hline$k$ & Thermal conductivity & $T_{a}$ & Ambient temperature \\
\hline C & Concentration & \multirow{2}{*}{\multicolumn{2}{|c|}{ Greek symbols }} \\
\hline$C_{l}$ & Concentration in liquid phase & & abols \\
\hline$C_{s}$ & Concentration in solid phase & $\rho$ & Density \\
\hline$C_{r e f}$ & Reference Concentration & $\mu$ & Viscosity \\
\hline$D$ & Diffusion coefficient of element & $\mu_{m}$ & magnetic permeability \\
\hline$Q_{\text {laser }}$ & Body heat source of laser & $\beta$ & Coefficient of volume expansion \\
\hline$Q_{\text {arc }}$ & Body heat source of arc & $\gamma$ & Surface tension \\
\hline$Q_{d}$ & Sensible heat from droplets & $\frac{d \gamma}{d T}$ & Temperature coefficient of surface tension \\
\hline$q_{\text {laser }}$ & Surface heat source of laser & $\sigma$ & Stefan-boltzmann constant \\
\hline$r$ & Radius & $\sigma_{j}$ & Radius of the arc pressure \\
\hline$H$ & Thickness of workpiece & $\varepsilon$ & Surface emissivity \\
\hline$L$ & Characteristic length & & \\
\hline
\end{tabular}

the experimental and numerical results. A finite element model was developed by Meng et al. [14] in order to understand the thermal behavior of large spot laser-MIG welding. In their calculation, the laser, the MIG torch and the droplet were treated as Gaussian plane, modified double ellipse, and uniform body heat source, separately. The temperature distribution, especially the brazing interface, and weld bead geometry were all numerically studied.

Although some progress was made on fluid flow and heat transfer of the melt pool, few researchers tried to address mass transfer for hybrid laser-MIG welding. Won-Ik Cho et al. [15] established a numerical model to simulate the alloying element distribution in $\mathrm{CO}_{2}$ laser-GMA hybrid welding. They found that the alloying element distributions might be affected by fluid flow. Despite the mass transfer in molten pool greatly affected the mechanical properties of the weld [5,10,16-18], the existing work on mass transfer and alloying element distribution was far from enough. The heat transfer and solute distribution in molten pool for hybrid laser-MIG welding was not fully understood. It was extremely essential to develop and improve the related numerical model to explore the heat and mass transfer mechanism systematically.

In this work, a 3D numerical model was established to analyze the thermal behavior and solute distribution in hybrid laser-MIG welding of aluminum alloy. A combined heat source for laser was adopted in this work, and the MIG torch was utilized as a surface heat source with distribution of Gaussian. The couple effect of laser beam and MIG torch was considered in the model. The driving forces, including electromagnetic force, surface tension and buoyancy, were taken into consideration. In addition, the droplet impact and arc pressure were taken into account to track the free surface. The redistribution of magnesium and zinc element in the molten pool was analyzed and compared. A detailed insight into the thermal behavior, fluid flow and solute distribution was provided in the work. Furthermore, the simulated geometry of weld pool and composition profile were compared with those from experimental results.

\section{Experimental procedure}

The A7N01 aluminum alloy and ER5356 of $1.2 \mathrm{~mm}$ in diameter were selected as base metal and welding wire respectively, and the composition of materials were presented in Table 1. A Nd:YAG laser combined with a MIG torch were utilized to implement hybrid laser-MIG welding. A $1 \mathrm{~kW}$ Nd:YAG laser manufacturing system with $1070 \mathrm{~nm}$ wavelength was used as laser power source, and a pulsed MIG weld machine, with the maximum current of $350 \mathrm{~A}$, was used as the source of arc power. The preparation of metallographic specimen was in the order of electric discharge cutting, mechanical milling and grinding, and then standard mechanical polishing. The dimension of samples was $60 \mathrm{~mm} \times 10 \mathrm{~mm} \times 6 \mathrm{~mm}$. To investigate the element distribution, the weld seam was observed by scanning electron microscopy (JSM-5800), equipped with energy dispersive spectrometer (LinkISIS S-530).

\section{Mathematical model}

In the work, a 3D model was developed to analyze the heat transfer and solute distribution in hybrid laser-MIG welding. Fig. 1 shows the

Table 1

Material compositions of A7N01 aluminum and ER5356 welding wire [8].

\begin{tabular}{|c|c|c|c|c|c|c|c|c|c|}
\hline Materials & $\mathrm{Mg}$ & $\mathrm{Zn}$ & $\mathrm{Fe}$ & Mn & $\mathrm{Si}$ & $\mathrm{Cr}$ & $\mathrm{Ti}$ & $\mathrm{Cu}$ & $\mathrm{Al}$ \\
\hline A7N01 & $1.0-2.0$ & $4.0-5.0$ & 0.35 & $0.2-0.7$ & $<0.30$ & $<0.30$ & $<0.20$ & $<0.20$ & Bal. \\
\hline ER5356 & $4.5-5.5$ & $<0.1$ & $<0.4$ & $0.05-0.2$ & $<0.25$ & $0.05-0.2$ & $0.06-0.2$ & $<0.10$ & Bal. \\
\hline
\end{tabular}




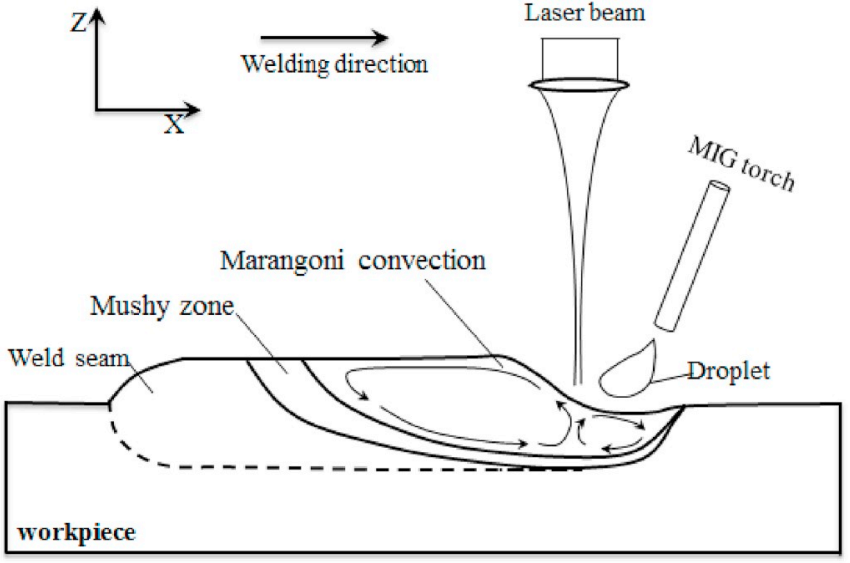

Fig. 1. Sketch map for hybrid laser-MIG welding.

sketch map for the laser-MIG welding, and some assumptions were made in the mathematical model $[17,19,20]$.

1. The fluid flow in the molten pool was assumed to be incompressible, Newtonian and laminar.

2. The thermophysical properties were taken not to depend on temperature, and different for liquid and solid phase.

3. The coefficient for energy absorption was supposed to be invariant.

4. For solid phase, there was no diffusion transport.

5. In the model of solidification for multicomponent alloy, a pseudobinary equivalent was supposed.

6. The loss of heat and composition due to vaporization was neglected, and the laser heat absorbed by the droplet was ignored.

7. The mushy region was supposed to be isotropic.

8. The composition of welding wire was assumed as $95 \%$ aluminum and $5 \%$ magnesium, while the composition of base metal was assumed as $95.5 \%$ aluminum and $4.5 \%$ zinc, any other elements were neglected.

\subsection{Governing equations}

According to the assumptions, the conservation equations of mass, momentum, energy and concentration are as follows.

$\frac{\partial \rho}{\partial t}+\frac{\partial\left(\rho u_{i}\right)}{\partial x_{i}}=0$

Table 2

Material properties of substrate and welding wire [29-31].

\begin{tabular}{lll}
\hline Property (Unit) & $\begin{array}{l}\text { Substrate } \\
\text { (A7N01) }\end{array}$ & $\begin{array}{l}\text { Welding wire } \\
\text { (ER5356) }\end{array}$ \\
\hline Solidus temperature $(\mathrm{K})$ & 858 & 813 \\
Liquidus temperature $(\mathrm{K})$ & 923 & 908 \\
Density of liquid metal $\left(\mathrm{kg} / \mathrm{m}^{3}\right)$ & 2700 & 2380 \\
Enthalpy of solidus temperature $(\mathrm{J} / \mathrm{kg})$ & $7.6 \times 10^{5}$ & $7.4 \times 10^{5}$ \\
Enthalpy of liquidus temperature $(\mathrm{J} / \mathrm{kg})$ & $1.1 \times 10^{6}$ & $1.03 \times 10^{6}$ \\
Specific heat of liquid $(\mathrm{J} /(\mathrm{kg} \cdot \mathrm{K}))$ & 1200 & 1135 \\
$\quad$ Specific heat of solid $(\mathrm{J} /(\mathrm{kg} \cdot \mathrm{K}))$ & 881 & 913 \\
Thermal conductivity of liquid $(\mathrm{W} /(\mathrm{m} \cdot$ & 80 & 83 \\
$\quad \mathrm{~K}))$ & & \\
Thermal conductivity of solid $(\mathrm{W} /(\mathrm{m} \cdot \mathrm{K}))$ & 101 & 108 \\
Effective mass diffusivity $\left(\mathrm{m}^{2} / \mathrm{s}\right)$ & $7 * 10^{-7}$ & $7^{*} 10^{-7}$ \\
Temperature coefficient of surface & $-1.55 \times 10^{-4}$ & $-1.7 \times 10^{-4}$ \\
$\quad$ tension $(\mathrm{N} /(\mathrm{m} \cdot \mathrm{K}))$ & & \\
Viscosity of liquid $(\mathrm{kg} /(\mathrm{m} \cdot \mathrm{s}))$ & $1.0 \times 10^{-3}$ & $1.0 \times 10^{-3}$ \\
\hline
\end{tabular}

$$
\begin{aligned}
\frac{\partial\left(\rho u_{j}\right)}{\partial t}+\frac{\partial\left(\rho u_{i} u_{j}\right)}{\partial x_{i}}= & \frac{\partial}{\partial x_{i}}\left(\mu \frac{\partial u_{j}}{\partial x_{i}}\right)-\frac{\partial P}{\partial x_{i}}+\frac{\partial}{\partial x_{j}}\left(\mu \frac{\partial u_{j}}{\partial x_{i}}\right)-V \frac{\partial\left(\rho u_{i}\right)}{\partial x} \\
& -C_{0}\left(\frac{\left(1-f_{l}\right)^{2}}{f_{l}^{3}+B}\right) u_{i}+F \\
\frac{\partial(\rho h)}{\partial t}+\frac{\partial\left(\rho u_{i} h\right)}{\partial x_{i}}= & \frac{\partial}{\partial x_{i}}\left(\frac{k}{C_{p}} \frac{\partial h}{\partial x_{i}}\right)-\frac{\partial(\rho \Delta H)}{\partial t}-\frac{\partial\left(\rho u_{i} \Delta H\right)}{\partial x_{i}}-V \frac{\partial(\rho h)}{\partial x} \\
& -V \frac{\partial(\rho \Delta H)}{\partial x}+Q_{\text {laser }} \\
\frac{\partial(\rho C)}{\partial t}+\frac{\partial\left(\rho u_{i} C\right)}{\partial x_{i}}= & \frac{\partial}{\partial x_{i}}\left(\rho D \frac{\partial C}{\partial x_{i}}\right)+\frac{\partial}{\partial x_{i}}\left(\rho D \frac{\partial\left(C_{l}-C\right)}{\partial x_{i}}\right) \\
& -\frac{\partial}{\partial x_{i}}\left(\rho f_{s}\left(C_{l}-C_{s}\right) u_{i}\right)
\end{aligned}
$$

The porous media term in the right-hand side of Equation (2) was represented on the basis of Carman-Kozeny equation [21-23]. $F$ is the volume force, including electromagnetic force and buoyancy caused by concentration and temperature variations. The electromagnetic force can be expressed as [24,25]:

$F_{L x}=-\frac{\mu_{m} I^{2}}{4 \pi^{2} \sigma_{j}^{2} r} \exp \left(-\frac{r^{2}}{2 \sigma_{j}^{2}}\right)\left[1-\exp \left(-\frac{r^{2}}{2 \sigma_{j}^{2}}\right)\right]\left(1-\frac{z}{H}\right)^{2} \frac{x}{r}$

$F_{L y}=-\frac{\mu_{m} I^{2}}{4 \pi^{2} \sigma_{j}^{2} r} \exp \left(-\frac{r^{2}}{2 \sigma_{j}^{2}}\right)\left[1-\exp \left(-\frac{r^{2}}{2 \sigma_{j}^{2}}\right)\right]\left(1-\frac{z}{H}\right)^{2} \frac{y}{r}$

$F_{L z}=-\frac{\mu_{m} I^{2}}{4 \pi^{2} \sigma_{j}^{2} r} \exp \left(-\frac{r^{2}}{2 \sigma_{j}^{2}}\right)\left[1-\exp \left(-\frac{r^{2}}{2 \sigma_{j}^{2}}\right)\right]\left(1-\frac{z}{H}\right)$

The expression of buoyancy is as follows:

$F_{b}=\rho g \beta\left(T-T_{r e f}\right)+\rho g \beta\left(C-C_{r e f}\right)$

The last two terms in Eq. (4) represent the solute partitioning at the liquid-solid interface [20]. The formulation of nominal concentration [26], density, thermal conductivity, heat capacity, and mass diffusion coefficient for mushy zone can be summarized as follows [20,27].

$C=f_{s} C_{s}+f_{l} C_{l}$

$\rho=f_{s} \rho_{s}+f_{l} \rho_{l}$

$k=\left(\frac{g_{s}}{k_{s}}+\frac{g_{l}}{k_{l}}\right)^{-1}$

$c=f_{s} c_{s}+f_{l} c_{l}$

$D=f_{l} D_{l}$

\subsection{Boundary conditions}

The boundary condition for energy can be given as

$-k \nabla T \cdot \boldsymbol{n}_{b}=q_{\text {laser }}+q_{a r c}+\mathrm{Q}_{\mathrm{d}}(x, y)-\sigma \varepsilon\left(T^{4}-T_{a}^{4}\right)-h_{c}\left(T-T_{a}\right)$

The detailed description of heat source model of laser and arc, and free surface evolution of the molten pool can be found in the literature [28].

The heat distribution of droplet was approximated as a Gaussian:

$Q_{d}(x, y)=\frac{C_{w} \rho_{w} \frac{\pi}{4} d_{w}^{2} U_{w}\left(T_{w}-T_{l}\right)}{2 \pi r_{f}^{2} f} \exp \left(\frac{x^{2}+y^{2}}{2 r_{f}^{2}}\right)$

The boundary condition for momentum can be expressed as 
Table 3

Processing parameters.

\begin{tabular}{ll}
\hline Parameter (Unit) & Value \\
\hline Voltage(V) & 21.3 \\
Welding current(A) & 150 \\
Effective laser radius (mm) & 0.15 \\
Laser power $(\mathrm{W})$ & 1000 \\
Wire diameter $(\mathrm{mm})$ & 1.2 \\
Scanning speed $(\mathrm{mm} / \mathrm{s})$ & 12 \\
Droplet temperature $(\mathrm{K})$ & 1923 \\
Wire feeding rate $(\mathrm{m} / \mathrm{min})$ & 9.3 \\
Ambient temperature(K) & 298 \\
Radius of droplet impact (mm) & 1.0 \\
Distance between MIG torch and laser $(\mathrm{mm})$ & 2 \\
Frequency of droplet transition $(\mathrm{Hz})$ & 317 \\
Stefan-Boltzmann constant $\left(\mathrm{W} /\left(\mathrm{m}^{2} \cdot \mathrm{K}^{4}\right)\right)$ & $5.67 \times 10^{-8}$ \\
Surface emissivity & 0.47 \\
\hline
\end{tabular}

$\mu \frac{\partial u}{\partial z} \cdot \boldsymbol{n}_{b}=f_{l} \frac{\partial \gamma}{\partial T}\left(\frac{d T}{d x} \cdot \boldsymbol{t}_{b x}\right)+f_{l} \frac{\partial \gamma}{\partial C}\left(\frac{d C}{d x} \cdot \boldsymbol{t}_{b x}\right)$

$\mu \frac{\partial \nu}{\partial z} \cdot \boldsymbol{n}_{b}=f_{l} \frac{\partial \gamma}{\partial T}\left(\frac{d T}{d y} \cdot \boldsymbol{t}_{b y}\right)+f_{l} \frac{\partial \gamma}{\partial C}\left(\frac{d C}{d y} \cdot \boldsymbol{t}_{b y}\right)$

$w \cdot \boldsymbol{n}_{\boldsymbol{b}}=0$

The Marangoni convection caused by temperature and concentration variation is represented at right-hand side in Eqs. (16) and (17).

\subsection{Numerical approach}

The heat transfer and solute distribution in hybrid laser-MIG welding was calculated and analyzed. The dimension of computational domain was $45 \times 10 \times 6 \mathrm{~mm}^{3}$ and $525 \times 120 \times 90$ grid points was adopted in the simulation. The closer to the heat source, the finer grid spacing. Half of work piece was adopted for simplification. In order to ensure the accuracy, The time step of $1 \mathrm{~ms}$ was adopted in the simulation The basic framework, the procedure of solution, and other information about the model have been described in details in a recent paper [28] and will not repeated here. Table 2 showed the thermophysical properties of A7N01 substrate and ER5356 welding wire. Processing parameters was shown in Table 3.

\section{Results and discussion}

\subsection{Fluid flow and heat transfer}

For hybrid laser-MIG welding, the distributions of liquid velocity and temperature were calculated and analyzed, respectively. Fig. 2 showed the fluid flow and temperature contour plot at different times. In the beginning, due to the heating of laser beam and MIG torch, the temperature for the heated zone increased rapidly, and the workpiece started to melt, then the molten pool formed. With the welding processing, the molten pool dimension gradually increased, as shown in Fig. 2. Because the MIG torch was in front of laser beam in the welding direction, the base metal melted due to MIG torch heat, then the laser was irradiated on the liquid metal directly, because of which the absorption for laser energy increased greatly. As a result, penetration enhanced significantly due to the Fresnel absorption and multiple reflections inside the keyhole. At 1.5s, the molten pool reached a steady state, and the highest temperature and liquid velocity in molten pool was $3088 \mathrm{~K}$ and $1.26 \mathrm{~m} / \mathrm{s}$, respectively.

From Fig. 2, because of negative temperature coefficient of surface tension, the liquid metal flowed out from the center to the periphery. Since the temperature inside the keyhole was higher than outside, the surface tension was smaller, and the liquid metal flowed toward that region. Due to the electromagnetic force, the liquid inside the pool tended to flow downward, and the penetration increased. Due to combined effect of electromagnetic force, surface tension, and buoyancy force, a counter-clockwise vortex formed in the melt pool.

The distribution of temperature and liquid velocity for YZ crosssection $(X=20 \mathrm{~mm})$ at the different times was shown in Fig. 3. With
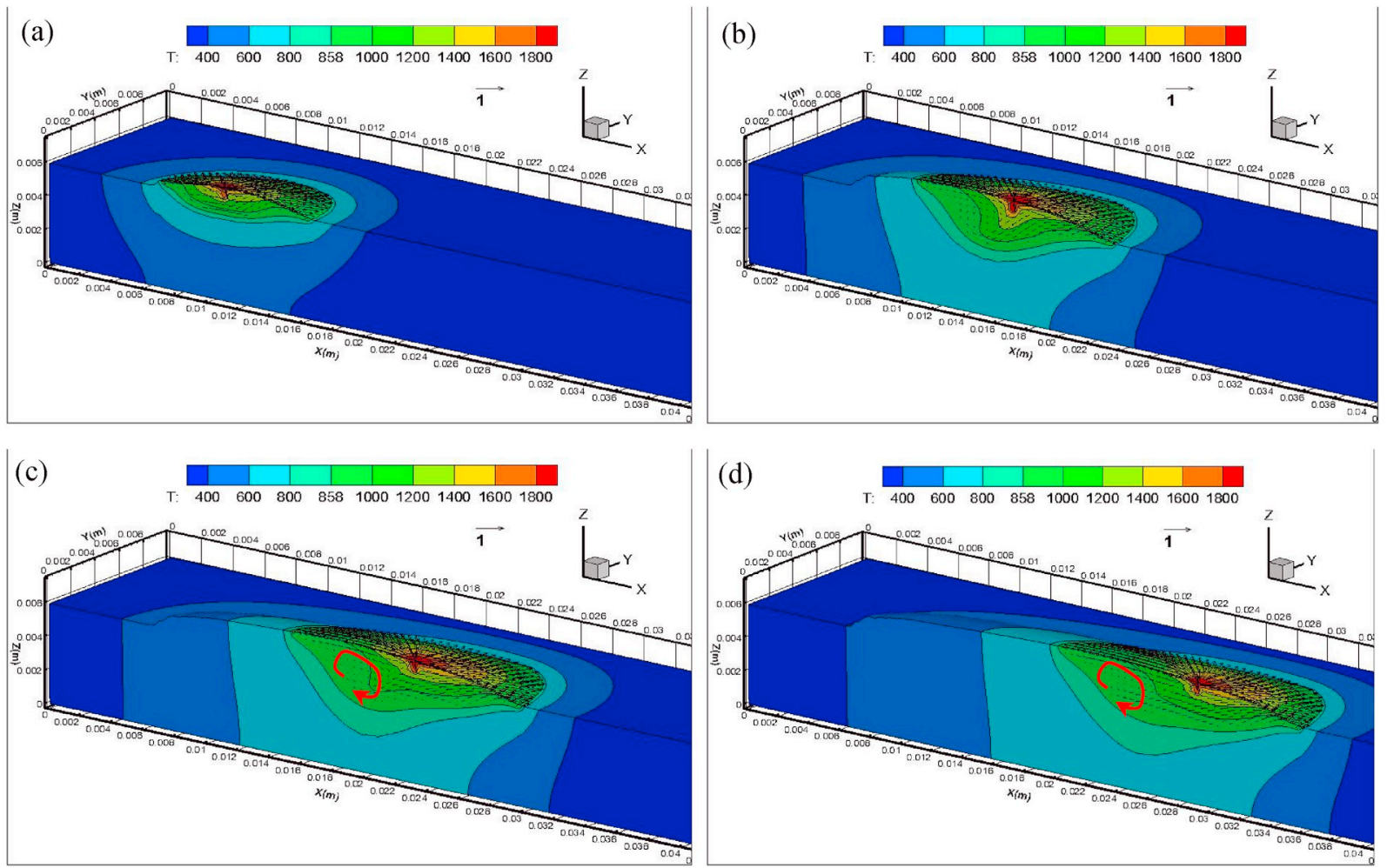

Fig. 2. Distribution of temperature and fluid velocity at different times. (a) $0.25 \mathrm{~s}$; (b) $0.75 \mathrm{~s}$; (c) $1.25 \mathrm{~s}$; (d) $1.50 \mathrm{~s}$. 
(a)
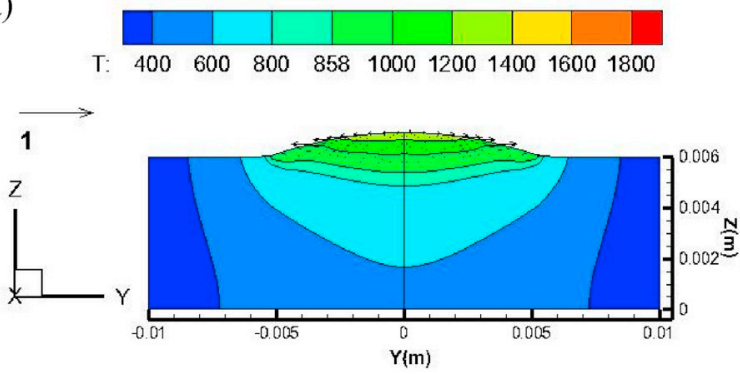

(c)

$400 \quad 600 \quad 800 \quad 858 \quad 10001200140016001800$

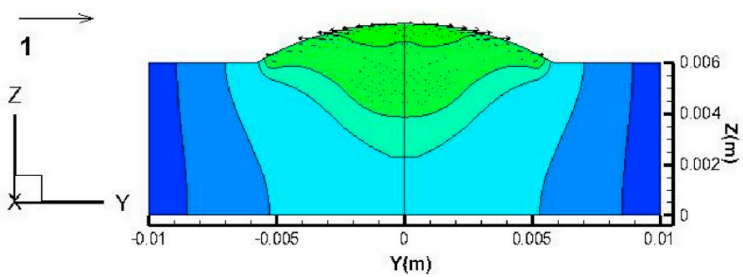

(b)
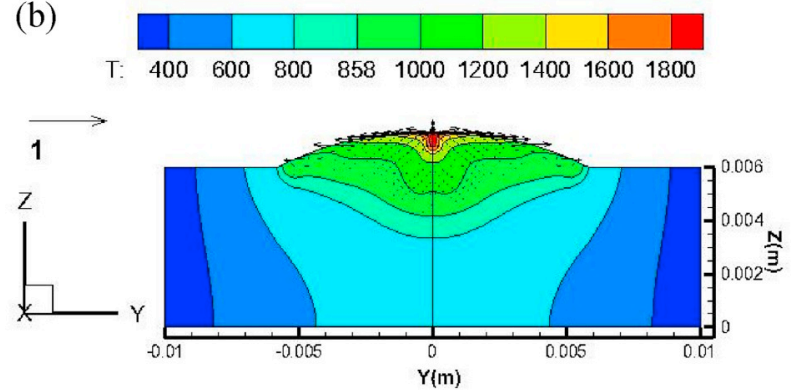

(d)
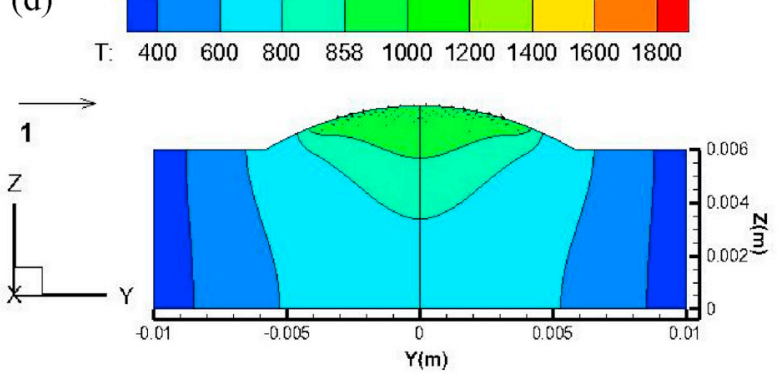

Fig. 3. Distribution of temperature and fluid velocity of YZ cross-section at different times. (a) $0.75 \mathrm{~s}$; (b) $1.0 \mathrm{~s}$; (c) $1.25 \mathrm{~s}$; (d) $1.50 \mathrm{~s}$.

(a)

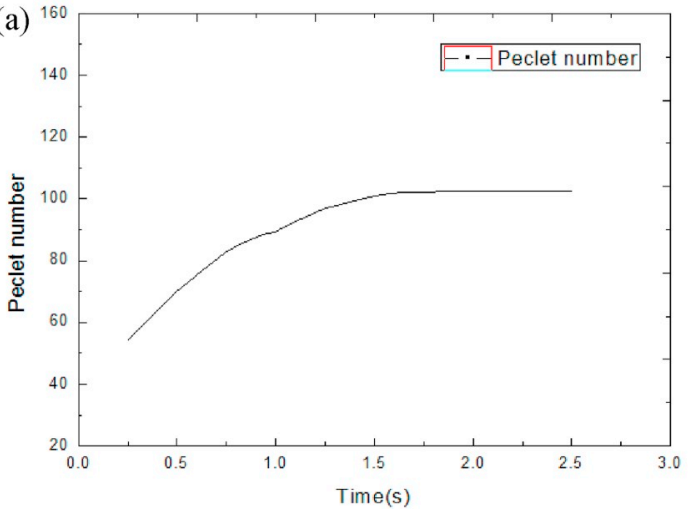

(b)

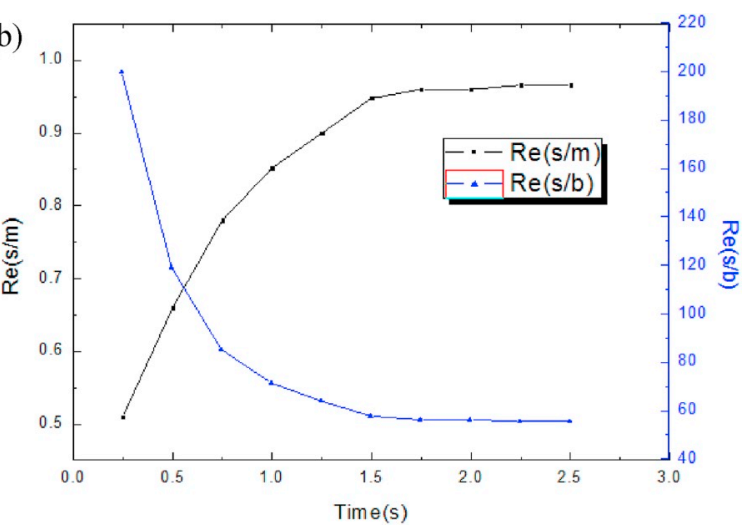

Fig. 4. Dimensionless number at different times. (a) Peclet number; (b) Reynolds number.

droplets entering the molten pool continuously, the height kept increasing until the molten pool reached a steady state. Due to the Fresnel absorption and multiple reflections, the maximum temperature and penetration occurred around the laser beam.

The importance of heat convection and conduction was denoted by the Peclet number [27].

$P e=\frac{U_{\max } \rho C_{p} L}{k}$

The relative significance of different driving forces can be measured by following dimensionless numbers. The relative significance of Marangoni force to buoyancy was express as

$\operatorname{Re}_{s / b}=\frac{M a}{G r}=\frac{|\partial \gamma / \partial T|}{g \beta L^{2} \rho}$

The relative importance of surface tension to electromagnetic force was calculated as

$\operatorname{Re}_{s / m}=\frac{M a}{\operatorname{Re}_{m}}=\frac{4 \pi^{2} L \Delta T|\partial \gamma / \partial T|}{\mu_{m} I^{2}}$

The variation of the relative dimensionless numbers was shown in Fig. 4. At the beginning, the Peclet number was about 50, then the dimension of molten pool continuously increased, and the convection was more and more stronger. Therefore, the Peclet number continuously increased until the molten pool reached a steady state. Similarly, the $\mathrm{Re}_{\mathrm{s} / \mathrm{m}}$ number increased at the initial stage until it stabilized, while, the $\mathrm{Re}_{\mathrm{s} / \mathrm{b}}$ number decreased due to the gradually increased dimension of the molten pool. From Fig. 4, the Peclet was on the order of $10^{2}$, and the convection dominated the heat transfer in the melt pool. Electromagnetic force and surface tension were on the same order, which mainly affected the liquid flow. The influence of buoyancy was very small. Under the combined effect of surface tension, electromagnetic force and buoyancy force, the fluid flow in the molten pool was quite strong.

\subsection{Solute distribution}

For aluminum alloy, the magnesium and zinc element could improve strength and corrosion resistance. Alloying elements were added to the liquid aluminum, and the property of the weld bead was improved due to the solution strengthening $[32,33]$. For hybrid laser-MIG welding of A7N01 aluminum alloy, the original magnesium element was present in the welding wire, and the original zinc element was present in the substrate. When the welding wire melted, the magnesium element was transferred to the liquid pool. Meanwhile, the base metal melted, the 

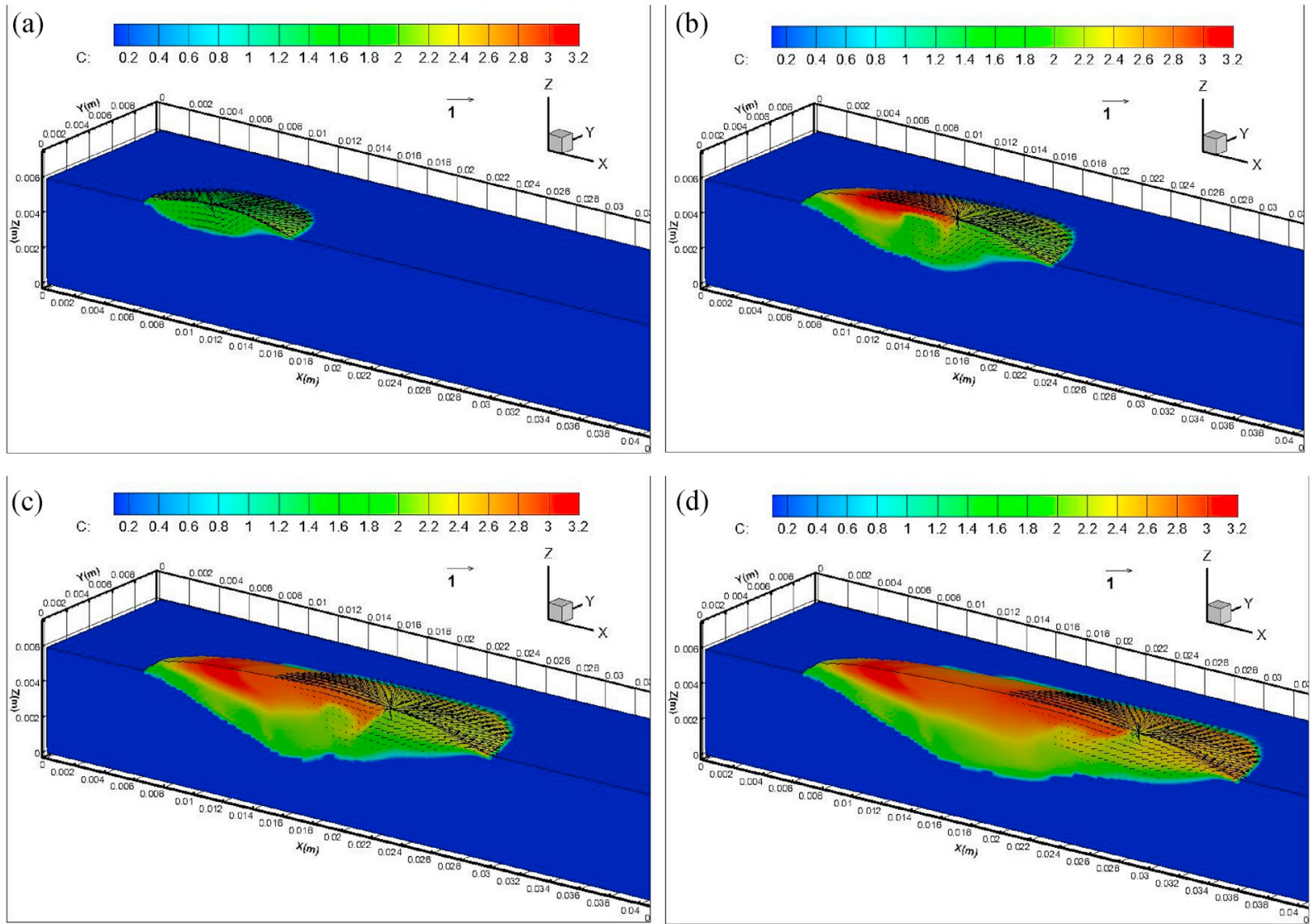

Fig. 5. Concentration of magnesium distribution at different times. (a) $0.25 \mathrm{~s}$; (b) $0.75 \mathrm{~s}$; (c) $1.25 \mathrm{~s}$; (d) $1.50 \mathrm{~s}$.

(a)
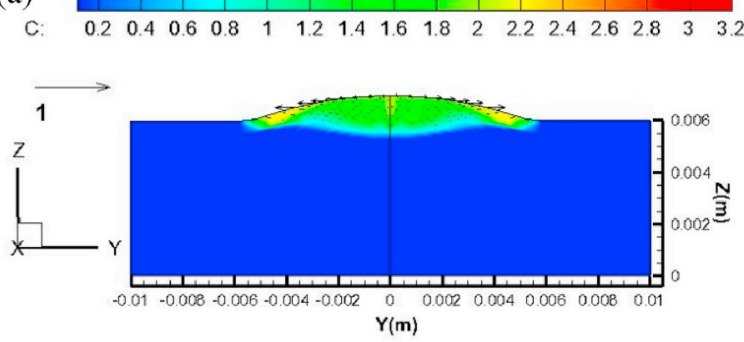

(c)
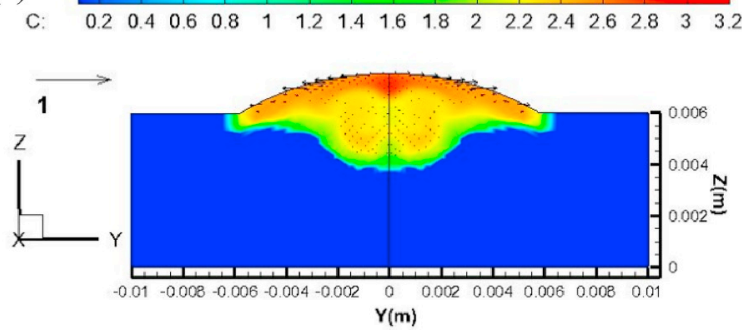

(b)

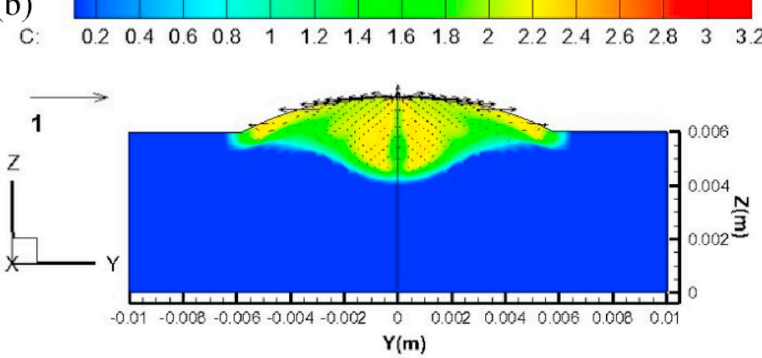

(d)

c: $\quad \begin{array}{lllllllllllllllll}0.2 & 0.4 & 0.6 & 0.8 & 1 & 1.2 & 1.4 & 1.6 & 1.8 & 2 & 2.2 & 2.4 & 2.6 & 2.8 & 3 & 3.2\end{array}$

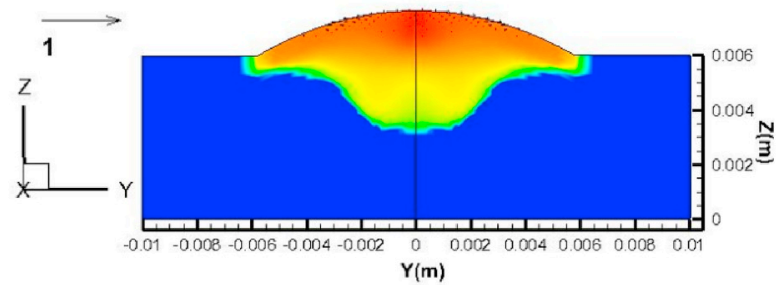

Fig. 6. Magnesium distribution of YZ cross-section at different times. (a) $0.75 \mathrm{~s}$; (b) $1.0 \mathrm{~s}$; (c) $1.25 \mathrm{~s}$; (d) $1.50 \mathrm{~s}$.

zinc element was carried to the molten pool. Then the magnesium and zinc element were redistributed in the liquid pool. In the simulation, the mass transfer process of droplets entering the molten pool was considered. In addition, the alloy element in the plate flow to the liquid pool and alloy element redistribution were also calculated. The magnesium concentration for different times was shown in Fig. 5.
In the initial stage, the molten pool formed, the additional welding wire melted continuously and transited to the liquid pool, then the concentration of magnesium element gradually increased. After the initial stage, Marangoni convection was strong, and the composition distribution in the molten pool quickly became more and more homogeneous. Due to the surface tension and convection, magnesium flowed 

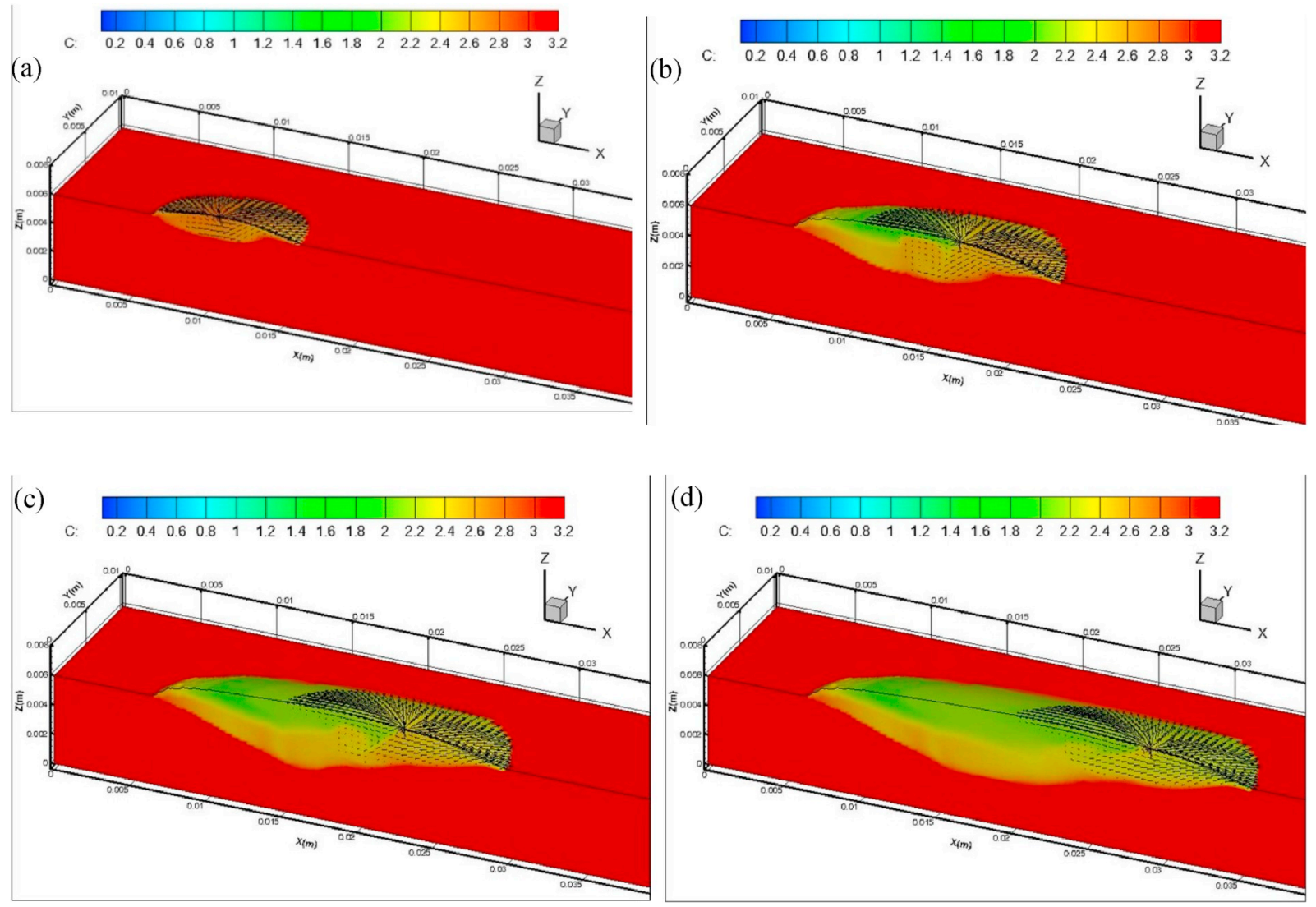

Fig. 7. Concentration of zinc distribution at different times. (a) $0.25 \mathrm{~s}$; (b) $0.75 \mathrm{~s}$; (c) 1.25s; (d) $1.50 \mathrm{~s}$.

(a)

c: $\quad \begin{array}{lllllllllllllllllll}0.2 & 0.4 & 0.6 & 0.8 & 1 & 1.2 & 1.4 & 1.6 & 1.8 & 2 & 2.2 & 2.4 & 2.6 & 2.8 & 3 & 3.2\end{array}$

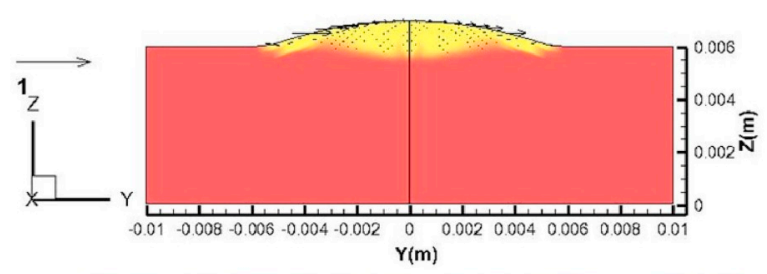

(c)

C: $\quad \begin{array}{llllllllllllllll}0.2 & 0.4 & 0.6 & 0.8 & 1 & 1.2 & 1.4 & 1.6 & 1.8 & 2 & 2.2 & 2.4 & 2.6 & 2.8 & 3 & 3.2\end{array}$
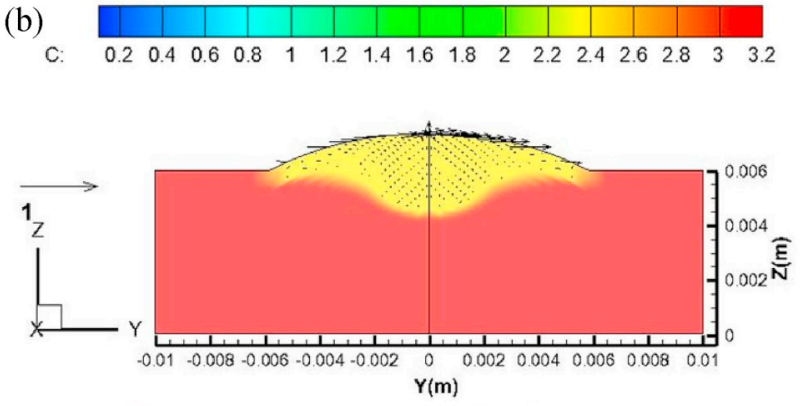

(d)

c: $\begin{array}{llllllllllllllllll}0.2 & 0.4 & 0.6 & 0.8 & 1 & 1.2 & 1.4 & 1.6 & 1.8 & 2 & 2.2 & 2.4 & 2.6 & 2.8 & 3 & 3.2\end{array}$
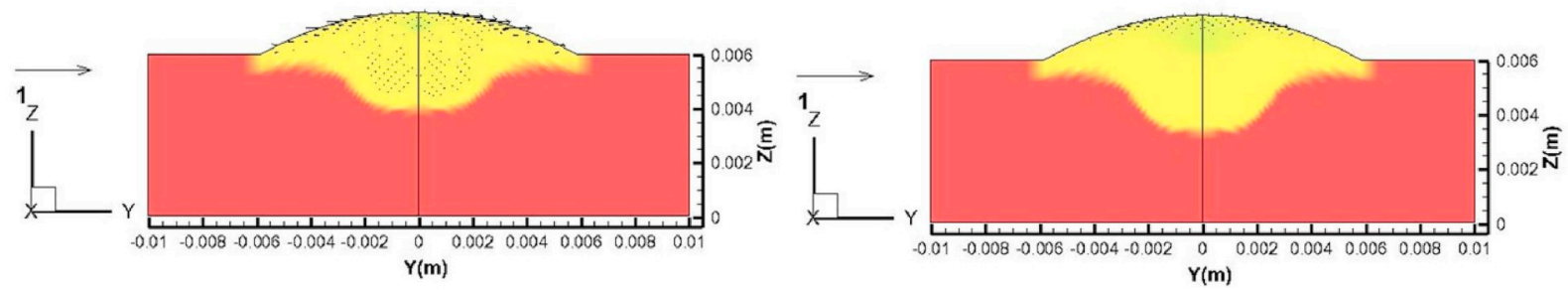

Fig. 8. Concentration distribution of zinc at different times. (a) $0.75 \mathrm{~s}$; (b) $1.0 \mathrm{~s}$; (c) $1.25 \mathrm{~s}$; (d) $1.50 \mathrm{~s}$.

from the pool center to the periphery and gathered in the rear of the pool. Most of the magnesium was present in the upper part of the liquid pool, and less magnesium was present in the lower part of the liquid pool due to the counter-clockwise vortex. The elemental magnesium was indicated by weight fraction. From the concentration profiles, the maximum magnesium concentration was $3.15 \%$ when the molten pool reached a steady state.

The magnesium concentration distribution of $\mathrm{YZ}$ cross-section $(\mathrm{X}=20 \mathrm{~mm}$ ) at different times was shown in Fig. 6. It was obvious that the magnesium concentration in the upper part of liquid pool was higher than that in the lower part of molten pool when the liquid pool reached a steady state. Convection and mass diffusion were the two mass 

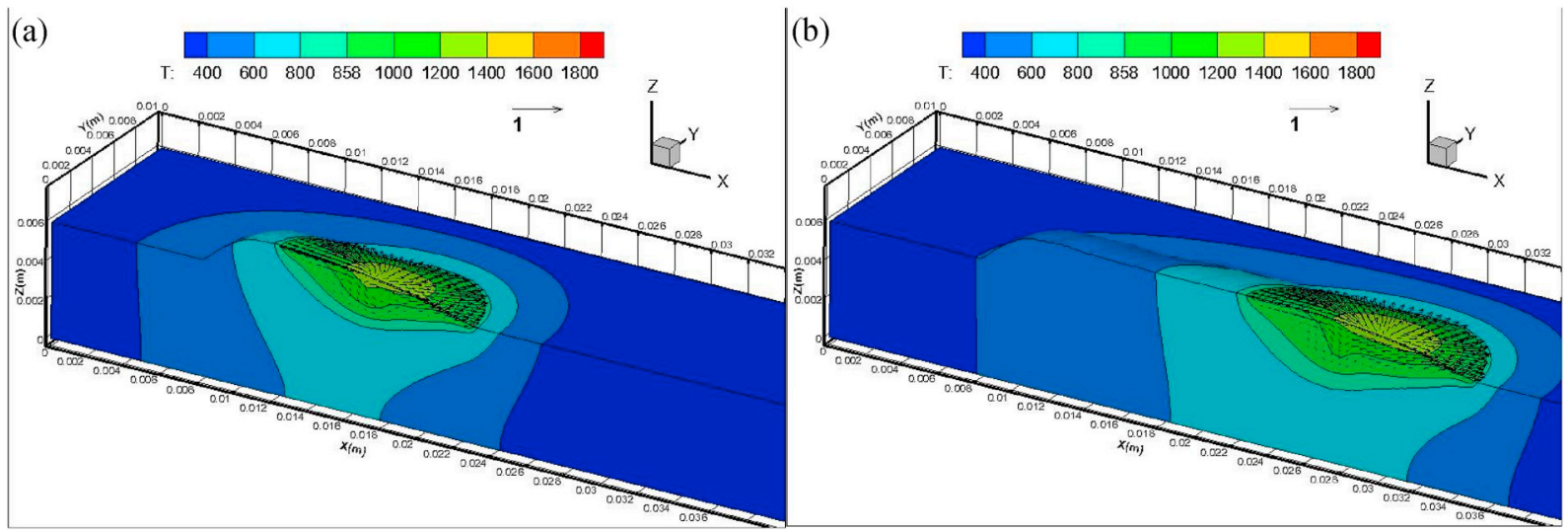

Fig. 9. Temperature and fluid velocity contour for MIG welding at different times. (a) $0.75 \mathrm{~s}$; (b) $1.50 \mathrm{~s}$.
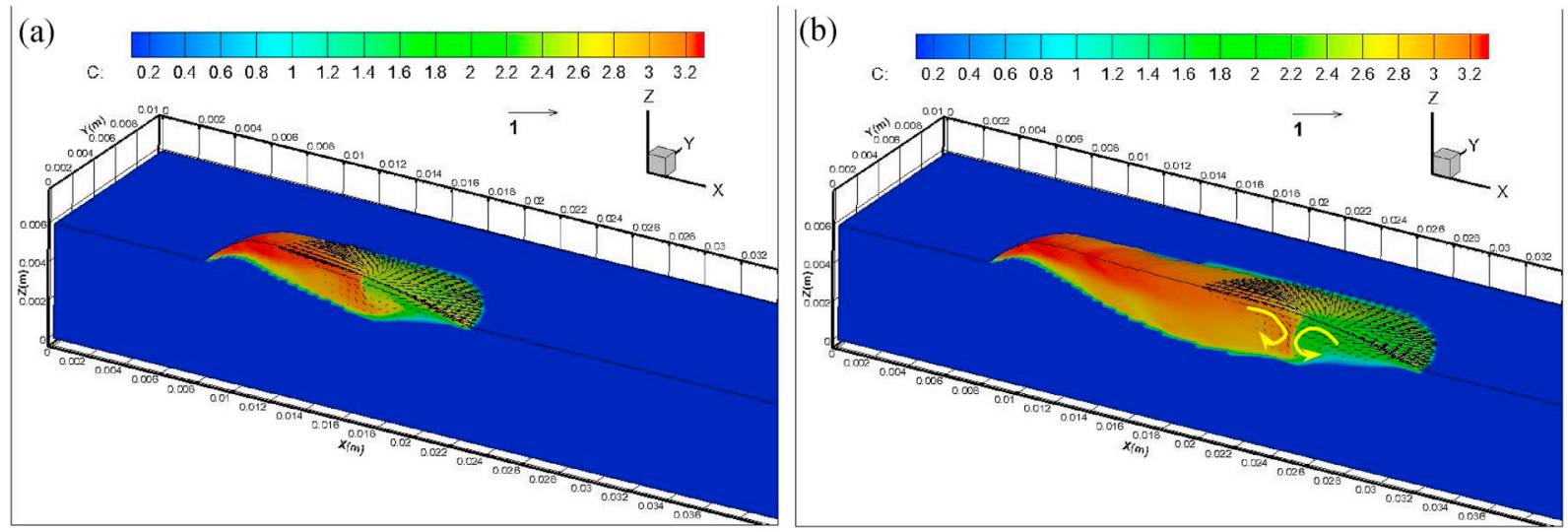

Fig. 10. Magnesium concentration distribution of MIG welding at different times. (a) $0.75 \mathrm{~s}$; (b) $1.50 \mathrm{~s}$.

transfer mechanisms in the melt pool. The importance of convection and diffusion can be denoted by the dimensionless number $P e_{c}, P e_{c}=\frac{u L}{D}$. Through calculation, the $P e_{c}$ was in the order of $10^{5}$ or $10^{6}$, and the mass transport in the liquid pool was governed by convection, to a lesser degree due to mass diffusion.

Fig. 7 showed the concentration of zinc distribution at different times. Compared with magnesium in the welding wire, zinc was present in the base metal, and its diffusion was different from that of the magnesium. At the initial stage, the workpiece melted, and only few droplets entered molten pool. The zinc concentration in the pool was close to the initial zinc concentration in the substrate. With welding processing, more and more weld wire melted and fell into the liquid pool, and the zinc element was diluted.

Fig. 8 showed the zinc concentration distribution of $\mathrm{YZ}$ cross-section $(X=20 \mathrm{~mm})$ at different times. With time going on, the concentration of zinc in the molten pool was continuously reduced. The zinc distribution at steady state was shown in Fig. 8(d). The concentration of zinc in the lower part of liquid pool was higher than that in the upper part of liquid pool, which was different from the distribution of magnesium. (a)

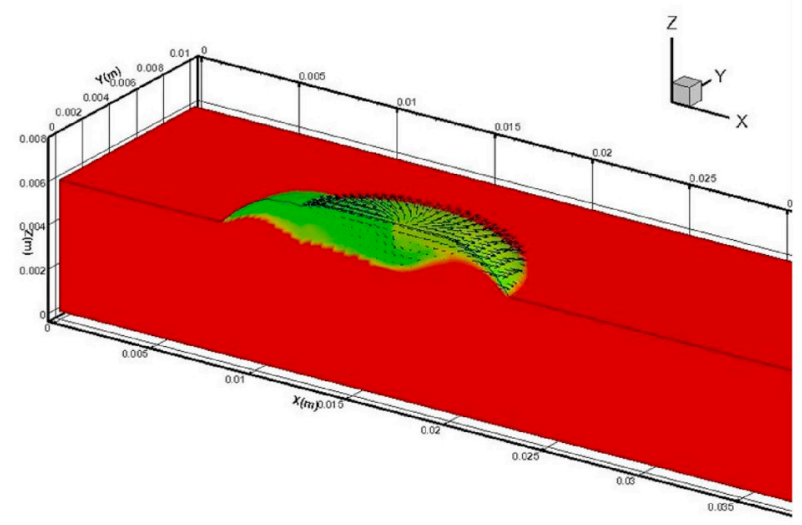

(b)
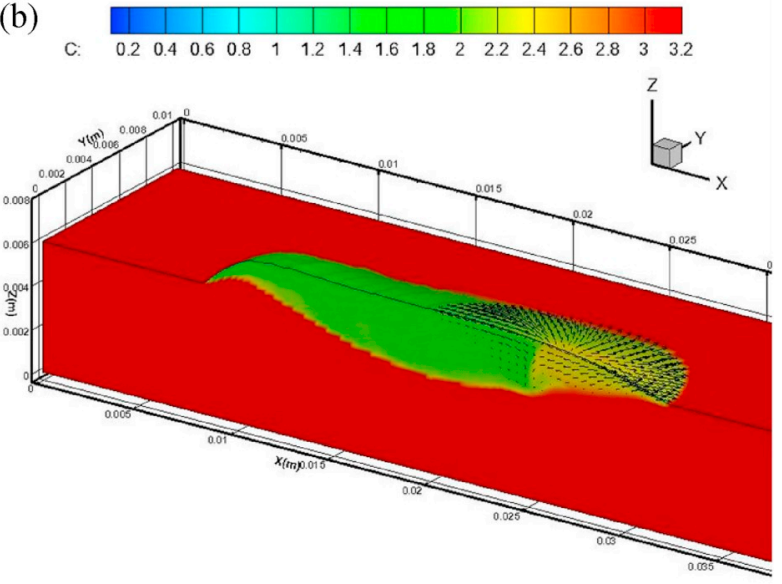

Fig. 11. Distribution of zinc concentration in MIG welding at different times. (a) $0.75 \mathrm{~s}$; (b) $1.50 \mathrm{~s}$. 
(a)
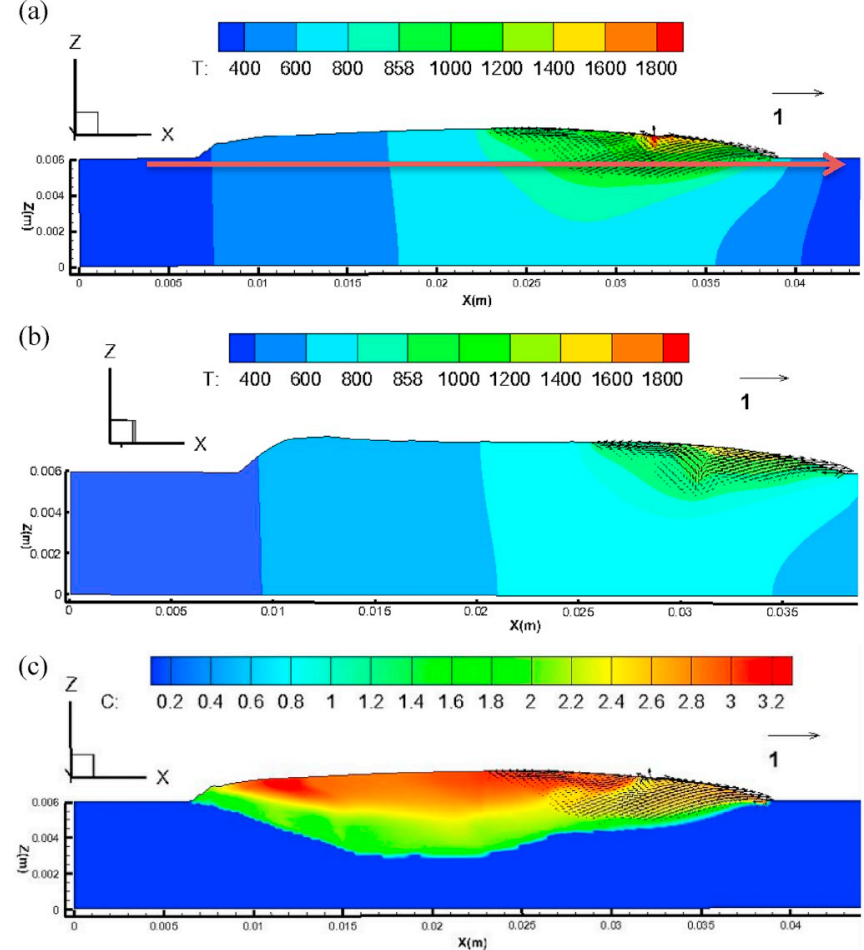

(d)
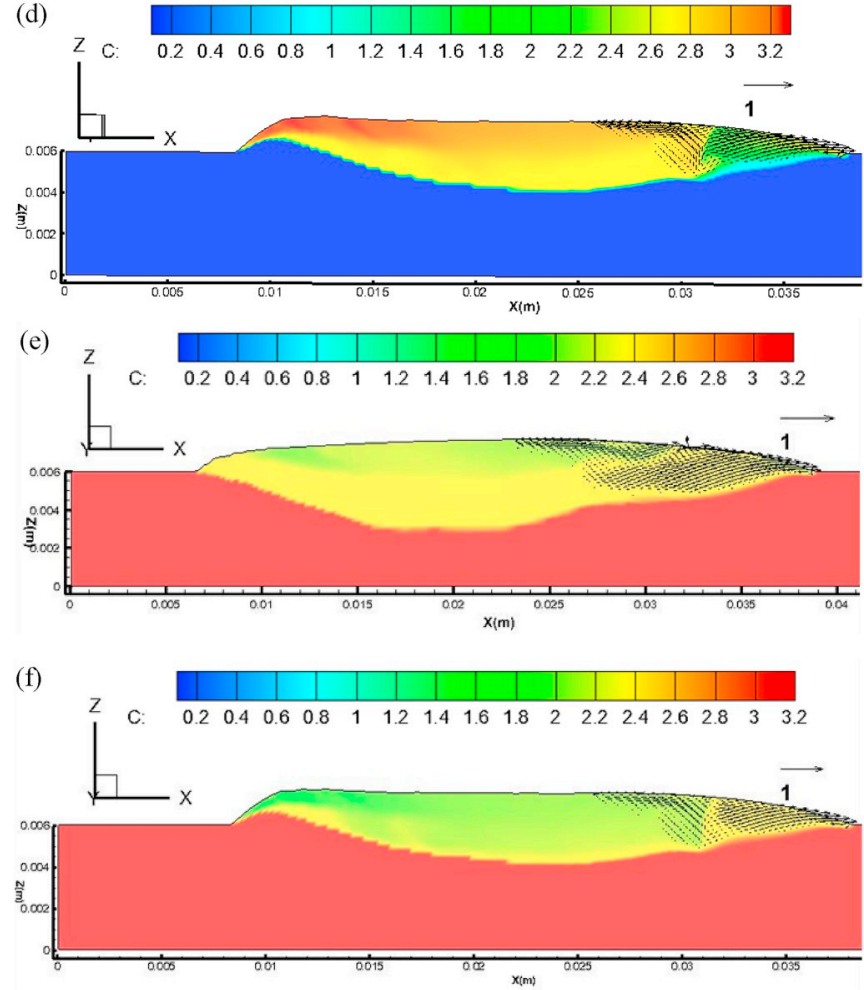

Fig. 12. Comparison between hybrid and MIG welding. (a) Distribution of temperature and fluid velocity in hybrid welding. (b) Distribution of temperature and fluid velocity in MIG welding. (c) Distribution of magnesium concentration in hybrid welding. (d) Distribution of magnesium concentration in MIG welding. (e) Distribution of zinc concentration in hybrid welding. (f) Distribution of zinc concentration in MIG welding.

\subsection{Comparison with $M I G$ welding}

Although the mass transfer was caused by droplet transition from welding wire to base metal, laser beam had a great effect on the behavior of mass transfer. In order to profoundly understand how laser beam affected the mass transfer, the relative results of MIG welding were analyzed and compared. Fig. 9 showed the distribution of temperature and liquid velocity for MIG welding at different times. It was shown that the maximum temperature and fluid velocity were $1366 \mathrm{~K}$ and $0.81 \mathrm{~m} / \mathrm{s}$ separately. When the molten pool reached a steady state, the Peclet number was 70, convection was weaker than that in hybrid welding. In hybrid welding, the molten pool was more homogenous due to the strong flow. In MIG welding, the maximum penetration was $1.7 \mathrm{~mm}$, while the maximum penetration was $2.4 \mathrm{~mm}$ in hybrid welding.

For mass transfer, the distribution of magnesium concentration in MIG welding at different times was shown in Fig. 10. The distribution of magnesium was inhomogeneous, and there was an insufficient mixing zone at the front pool. Under the surface tension, electromagnetic force and buoyancy force, there was two vortexes in the molten pool. The vortexes made the magnesium distribution divided into two zones, and the magnesium concentration in the rear of the pool was obviously higher than that in front of the pool. From the concentration profiles, the maximum magnesium concentration was $3.6 \%$.

Fig. 11 showed the distribution of zinc concentration in MIG welding at different times, which was different from the magnesium distribution. The distribution of zinc was inhomogeneous in the liquid pool, and the zinc concentration in the front of the liquid pool was obviously higher than that in the rear of the molten pool.

When the molten pool reached a steady state, the comparison between hybrid and arc welding was shown in Fig. 12. The XZ section was selected to compare and analyze the temperature, fluid velocity distribution, magnesium and zinc concentration distribution. From Fig. 12(a) and (b), in comparison to MIG welding, the fluid flow was much stronger in hybrid welding, and the length and penetration of the molten pool in hybrid welding were larger than that in MIG welding. It was shown that laser beam made the fluid stronger, and greatly changed the liquid flow in the molten pool. From Fig. 12(c) and (d), the concentration of magnesium was redistributed under the strong flow for hybrid laser-MIG welding, and the magnesium distribution was quite different. In MIG welding, the fluid was not intense enough, and the magnesium element was insufficiently mixed at the front of the pool. It was obvious that laser beam had a great effect on the magnesium distribution. For Fig. 12(e) and (f), the effect of laser beam on zinc distribution was similar.

In order to quantify the difference between the hybrid welding and MIG welding, a scanning track was selected as shown in Fig. 12(a). The variation of temperature, fluid velocity, magnesium concentration and zinc concentration along the scanning track was shown in Fig. 13.

From Fig. 13(a), for hybrid welding, the maximum temperature was $1281 \mathrm{~K}$, and the maximum temperature occurred around the laser beam. For MIG welding, the maximum temperature was $1032 \mathrm{~K}$, and the maximum temperature occurred around the MIG torch. From Fig. 13(b), for hybrid welding, the maximum fluid velocity was $0.43 \mathrm{~m} / \mathrm{s}$, the liquid flow was intense in the melt pool. The maximum fluid velocity was caused by Marangoni convection, and occurred at the periphery of the molten pool. For MIG welding, the maximum fluid velocity was $0.14 \mathrm{~m} /$ $\mathrm{s}$, and the maximum fluid velocity occurred around the MIG torch. From Fig. 13(c), for hybrid welding, the maximum magnesium concentration was $2.8 \%$, the magnesium content changed gradually, and there was no big fluctuation. For MIG welding, the maximum magnesium concentration was $3.2 \%$. Due to insufficient mixing zone at the front of the pool, there was relatively large fluctuation and there was a ladder-like mutation at the front of the pool, where the concentration was $1.9 \%$. From Fig. 13(d), for hybrid welding, the distribution of zinc concentration in the melt pool was homogeneous, and the concentration was $1 \%$. For MIG welding, the maximum zinc concentration in the liquid pool was $2.3 \%$, and the minimum magnesium concentration was $1.6 \%$. Due to the nonuniformity of the fluid flow, there were oscillation and ladder-like mutation at front of the melt pool. In conclusion, the liquid metal of molten pool was quite strong, and the solute was thoroughly mixed in hybrid laser-MIG welding. However, for MIG welding, there was a distinct 
(a)

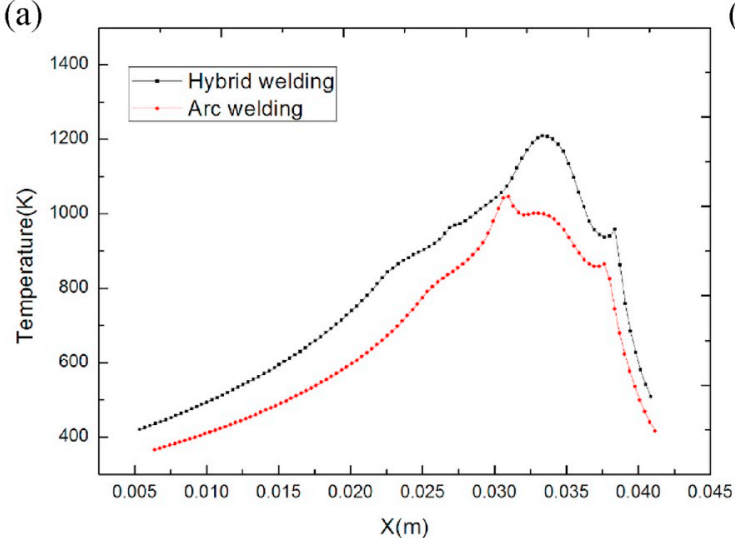

(b) 00

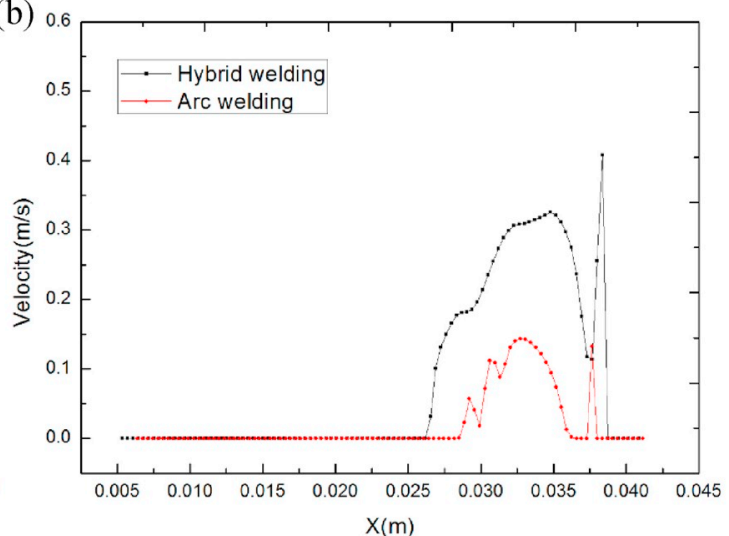

(c)

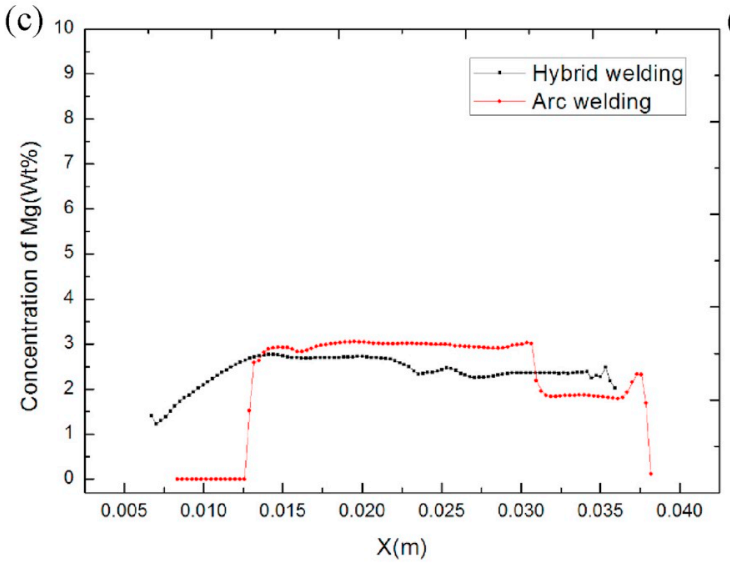

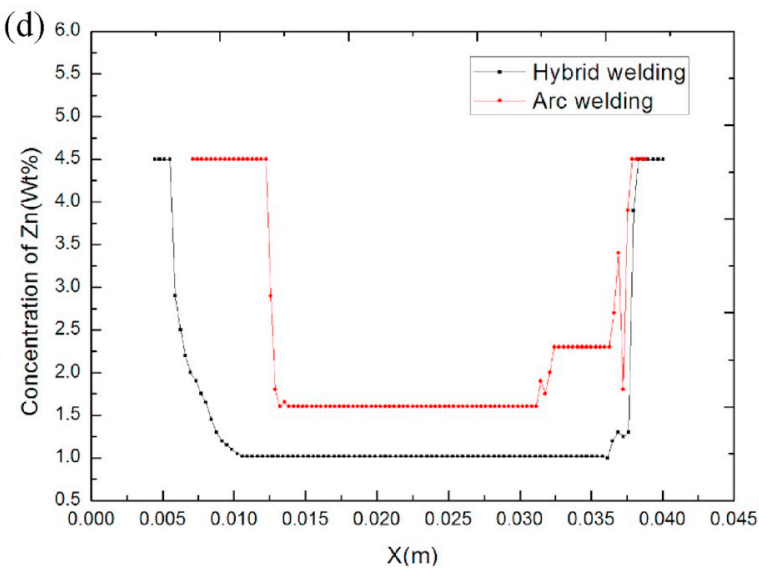

Fig. 13. Comparison between hybrid and MIG welding. (a) Temperature distribution. (b) Fluid velocity distribution. (c) Magnesium concentration. (d) Zinc concentration.

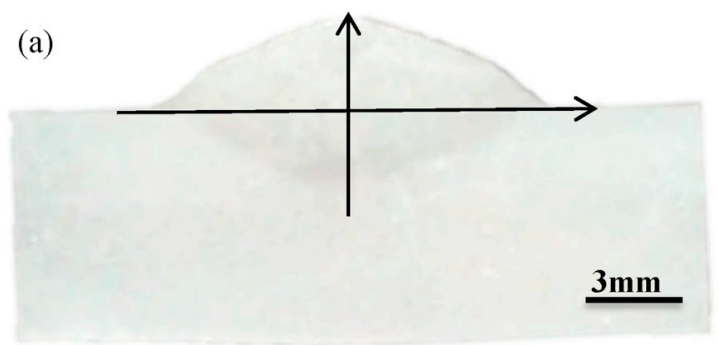

(c)

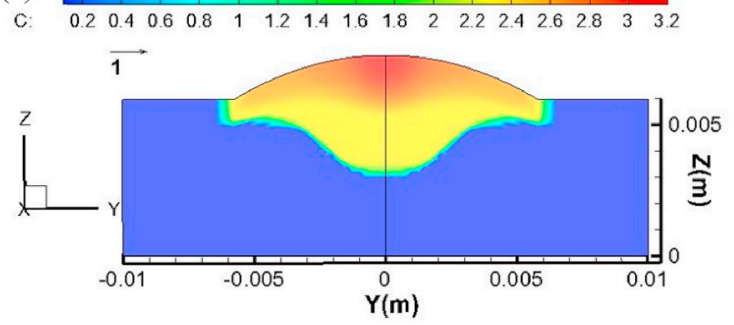

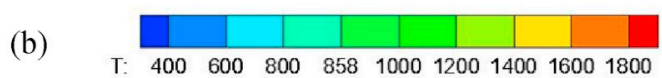

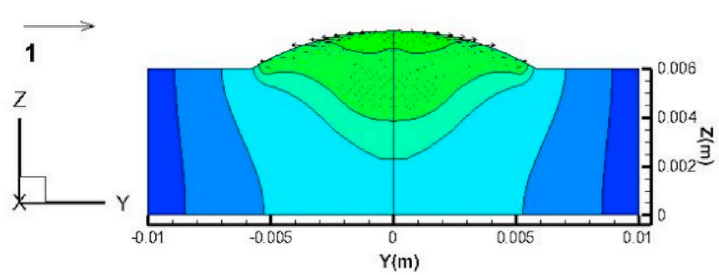

(d)
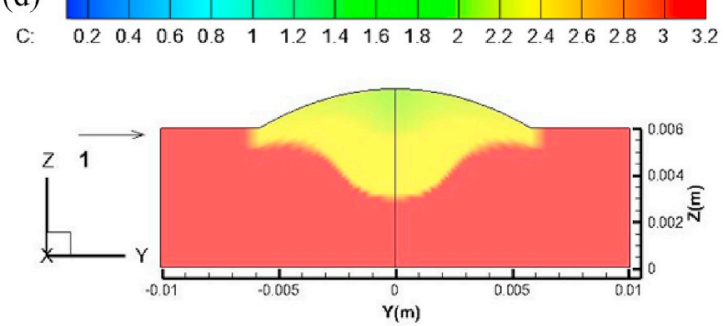

Fig. 14. Simulated and experimental results of YZ cross-section. (a) experiment (b) the temperature and fluid velocity distribution (c) the distribution of magnesium concentration (d) the distribution of zinc concentration.

insufficient mixing zone at the front of the pool.

\subsection{Experimental verification}

Experiments for hybrid welding were performed to verify the simulated results. When the molten pool reached a steady state, the YZ sections for simulated and experimental contour was shown in Fig. 14. It was shown that the simulated molten pool geometry was in good agreement with the experimental geometry. It was obvious that the concentration of magnesium in upper part of the pool was much higher, 

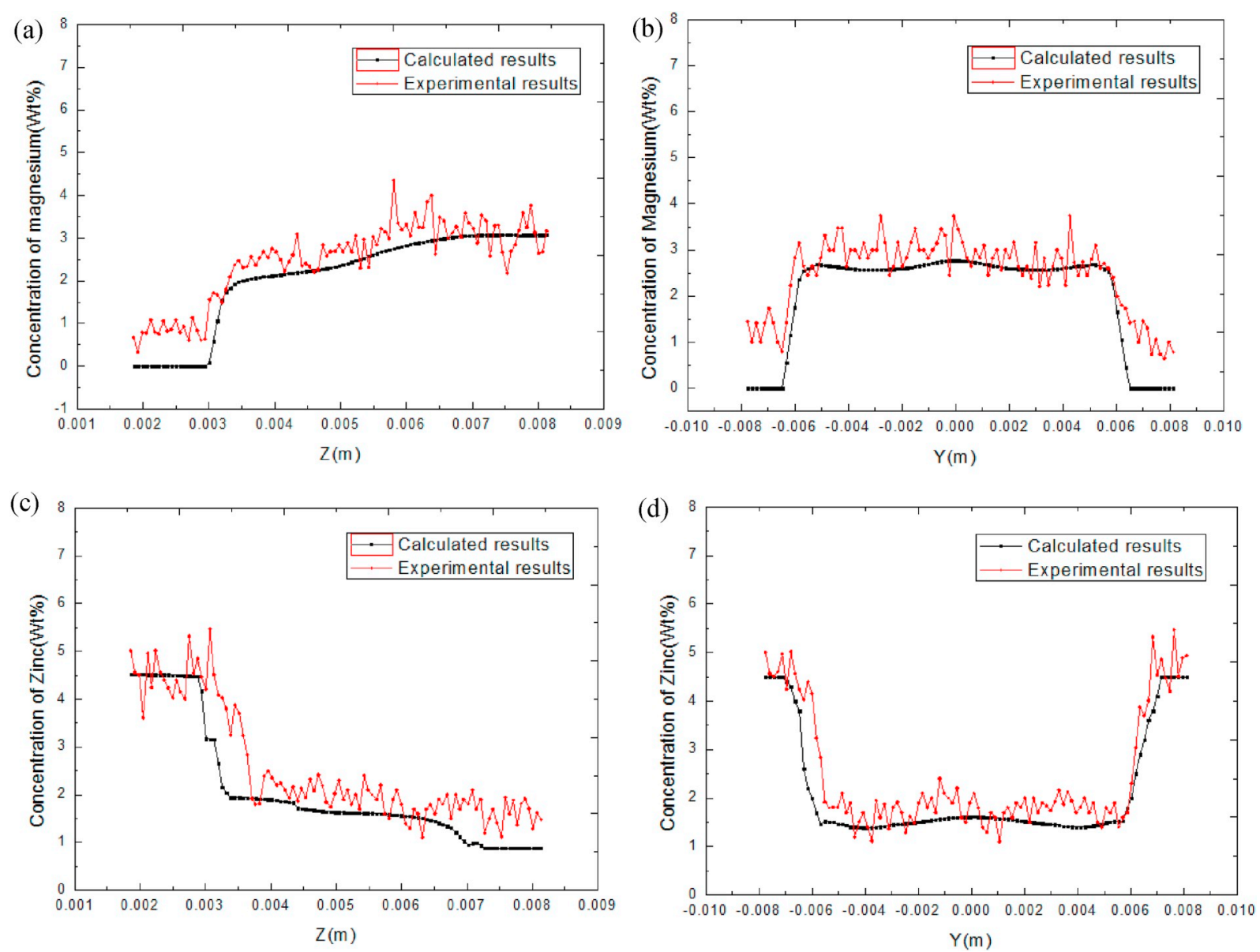

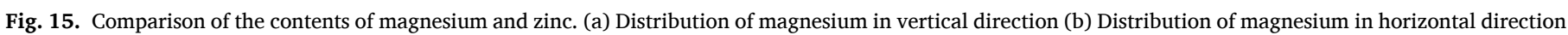
(c) Distribution of zinc in vertical direction (d) Distribution of zinc in horizontal direction.

while the distribution of zinc concentration was different. To further verify the simulation, two scanning tracks were selected to compare the contents of magnesium and zinc, as shown in Fig. 14(a).

Fig. 15 showed the comparison between experimental and calculated results for YZ cross-section. From Fig. 15, it was observed that the calculated concentration was a little lower than the experimental results, and the discrepancy was potentially due to some assumptions in calculation. Elements in alloys, except for magnesium, zinc and aluminum, were neglected. In addition, the temperature effect on absorption coefficient and thermo-physical properties was ignored. Even so, the calculated and experimental results were in close agreement, which showed the rationality of the mathematical model proposed in this work.

The proposed numerical model was contributed to profoundly understand the transport phenomena in the melt pool and provided the theoretical basis for the processing experiment. The research had a great significance to effectively control and optimize the welding process. It was promising that the model will be further developed to include solidification behavior and segregation of solute element during hybrid laser-MIG welding process. The relevance between thermal behavior and mechanical properties was the challenges for further investigation.

\section{Conclusions}

The objective of the study was to understand profoundly the thermal behavior and mass transport during hybrid laser-MIG welding of aluminum alloy. The temperature and fluid velocity distribution, and solute transport of magnesium and zinc were present. The computed and experimental results agreed well with each other to validate the mathematical model. Some conclusions were as follows:

1. For hybrid laser-MIG welding, the maximum temperature and liquid velocity was $3088 \mathrm{~K}$ and $1.26 \mathrm{~m} / \mathrm{s}$, respectively. When the molten pool reached a steady state, the Peclet number was more than $10^{2}$, and convection dominated the heat transfer. For hybrid welding, the convection was strong, and it made the molten pool tend to be homogenous.

2. For solute distribution in hybrid welding, the convection also played a dominant role. The maximum magnesium concentration was $3.15 \%$, and the concentration in upper part of the pool was higher than that in lower part. Though evolution of the zinc concentration was different, and the zinc concentration in upper part of the pool was lower than that in lower part.

3. For MIG welding, the maximum magnesium concentration was $3.6 \%$, and there was an obvious insufficient mixing zone at the front of the pool. The solute distribution in the hybrid welding was more uniform than that in MIG welding.

4. The quality of weld joint depended on the fluid flow, heat transfer, and mass transport in the molten pool, and the developed model can be utilized for optimization and control during hybrid laser-MIG welding process.

\section{Declaration of competing interest}

We declare that we have no conflict of interest. This manuscript is original and has never been published elsewhere. It is not being submitted to any other journal. All authors have agreed to submit it to the journal. 


\section{Acknowledgements}

The work was supported by a grant from National Natural Science Foundation of China, under grant numbers 11672304 and 11502269.

\section{References}

[1] W.M. Steen, Arc augmented laser processing of materials, J. Appl. Phys. 51 (1980) 5636-5641.

[2] T. Luijendijk, Welding of dissimilar aluminium alloys, J. Mater. Process. Technol. 103 (2000) 29-35.

[3] Z.H. Rao, S.M. Liao, H.L. Tsai, Modelling of hybrid laser-GMA welding: review and challenges, Sci. Technol. Weld. Join. 16 (2013) 300-305.

[4] E. Le Guen, R. Fabbro, M. Carin, F. Coste, P. Le Masson, Analysis of hybrid Nd:Yag laser-MAG arc welding processes, Opt. Laser. Technol. 43 (2011) 1155-1166.

[5] S. Liu, F. Liu, C. Xu, H. Zhang, Experimental investigation on arc characteristic and droplet transfer in CO2 laser-metal arc gas (MAG) hybrid welding, Int. J. Heat Mass Transf. 62 (2013) 604-611.

[6] W. Piekarska, M. Kubiak, Three-dimensional model for numerical analysis of thermal phenomena in laser-arc hybrid welding process, Int. J. Heat Mass Transf. 54 (2011) 4966-4974.

[7] B. Ribic, R. Rai, T. DebRoy, Numerical simulation of heat transfer and fluid flow in GTA/Laser hybrid welding, Sci. Technol. Weld. Join. 13 (2013) 683-693.

[8] H. Miao, G. Yu, X. He, S. Li, X. Chen, Comparative study of hybrid laser-MIG leading configuration on porosity in aluminum alloy bead-on-plate welding, Int. J. Adv. Manuf. Technol. 91 (2017) 2681-2688.

[9] M. Moradi, M. Ghoreishi, J. Frostevarg, A.F.H. Kaplan, An investigation on stability of laser hybrid arc welding, Opt. Lasers Eng. 51 (2013) 481-487.

[10] L. Zhao, T. Sugino, G. Arakane, S. Tsukamoto, Influence of welding parameters on distribution of wire feeding elements in CO2laser GMA hybrid welding, Sci. Technol. Weld. Join. 14 (2013) 457-467.

[11] J. Zhou, H.L. Tsai, Modeling of transport phenomena in hybrid laser-MIG keyhole welding, Int. J. Heat Mass Transf. 51 (2008) 4353-4366.

[12] Z. Gao, Y. Wu, J. Huang, Analysis of weld pool dynamic during stationary laser-MIG hybrid welding, Int. J. Adv. Manuf. Technol. 44 (2009) 870-879.

[13] I. Bendaoud, S. Matteï, E. Cicala, I. Tomashchuk, H. Andrzejewski, P. Sallamand, A. Mathieu, F. Bouchaud, The numerical simulation of heat transfer during a hybrid laser-MIG welding using equivalent heat source approach, Opt. Laser. Technol. 56 (2014) 334-342.

[14] X. Meng, G. Qin, Y. Su, B. Fu, Y. Ji, Numerical simulation of large spot laser + MIG arc brazing-fusion welding of $\mathrm{Al}$ alloy to galvanized steel, J. Mater. Process. Technol. 222 (2015) 307-314.

[15] W.-I. Cho, S.-J. Na, M.-H. Cho, J.-S. Lee, Numerical study of alloying element distribution in CO2 laser-GMA hybrid welding, Comput. Mater. Sci. 49 (2010) 792-800.

[16] A.H. Faraji, M. Goodarzi, S.H. Seyedein, C. Maletta, Effects of welding parameters on weld pool characteristics and shape in hybrid laser-TIG welding of AA6082 aluminum alloy: numerical and experimental studies, Weld. World 60 (2015) $137-151$.

[17] A. Farzadi, S. Serajzadeh, A.H. Kokabi, Investigation of weld pool in aluminum alloys: geometry and solidification microstructure, Int. J. Therm. Sci. 49 (2010) 809-819.

[18] P. Praveen, P.K.D.V. Yarlagadda, Meeting challenges in welding of aluminum alloys through pulse gas metal arc welding, J. Mater. Process. Technol. 164-165 (2005) 1106-1112.

[19] X. He, L. Song, G. Yu, J. Mazumder, Solute transport and composition profile during direct metal deposition with coaxial powder injection, Appl. Surf. Sci. 258 (2011) 898-907.

[20] Y. Hu, X. He, G. Yu, Z. Ge, C. Zheng, W. Ning, Heat and mass transfer in laser dissimilar welding of stainless steel and nickel, Appl. Surf. Sci. 258 (2012) 5914-5922.

[21] W.D. Bennon, F.P. Incropera, A continnum model for momentum heat and species transport in binary solid liquid-phase change systems-I. Model formulation, Int. J. Heat Mass Transf. 30 (1987) 2160-2170.

[22] W.D. Bennon, F.P. Incropera, A continnum model for momentum heat and species transport in binary solid liquid-phase change systems- I I. Application to solidification in a rectangular cavity, Int. J. Heat Mass Transf. 30 (1987) 2171-2187.

[23] W.H. Kim, H.G. Fan, S.J. Na, A mathematical model of gas tungsten arc welding considering the cathode and the free surface of the weld pool, Metall. Mater. Trans. B 28B (1997) 679-686.

[24] C.S. Wu, L. Dorn, Computer simulation of fluid dynamics and heat transfer in fullpenertrated TIG weld pools with surface depression, Comput. Mater. Sci. 2 (1994) $341-349$.

[25] C.S. Wu, K.C. Tsao, Modelling the three-dimensional fluid flow and heat transfer in a moving weld pool, Eng. Comput. 7 (3) (1990) 241-248.

[26] V.R. Voller, A.D. Brent, C. Prakash, The modeling of heat, mass and solute transport in solidification systems, Int. J. Heat Mass Transf. 32 (1989) 1719-1731.

[27] X. He, P.W. Fuerschbach, T. DebRoy, Heat transfer and fluid flow during laser spot welding of 304 stainless steel, J. Phys. D Appl. Phys. 36 (2003) 1388-1399.

[28] X. Chen, G. Yu, X. He, S. Li, H. Miao, Effect of droplet impact on molten pool dynamics in hybrid laser-MIG welding of aluminum alloy, Int. J. Adv. Manuf. Technol. 96 (2018) 209-222.

[29] G.M.D. Cantin, J.A. Francis, Arc power and efficiency in gas tungsten arc welding of aluminium, Sci. Technol. Weld. Join. 10 (2013) 200-210.

[30] M. Gao, S. Mei, Z. Wang, X. Li, X. Zeng, Process and joint characterizations of laser-MIG hybrid welding of AZ31 magnesium alloy, J. Mater. Process. Technol. 212 (2012) 1338-1346.

[31] H.L. Wei, J.W. Elmer, T. DebRoy, Three-dimensional modeling of grain structure evolution during welding of an aluminum alloy, Acta Mater. 126 (2017) 413-425.

[32] W. Woo, H. Choo, Softening behaviour of friction stir welded $\mathrm{Al}$ 6061-T6 and Mg AZ31B alloys, Sci. Technol. Weld. Join. 16 (2013) 267-272.

[33] L. Zhang, X. Li, Z. Nie, H. Huang, J. Sun, Softening behavior of a new Al-Zn-Mg-Cu alloy due to TIG welding, J. Mater. Eng. Perform. 25 (2016) 1870-1879. 